\title{
LA AMBIGÜEDAD DEL NOTARIO AUXILIAR
}

\author{
The ambiguity of the auxiliary notary
}

Carlos Alberto VILLAFUERTE MARTÍNEZ

"Dime las leyes que tienes, y te diré la sociedad en la que te encuentras".

Luigi Ferrajoli

Sumario:

I. Introducción. II. El origen y evolución del notario auxiliar. II.1. El imperio de Maximiliano. II.2. Ley Orgánica de Escribanos del Estado de Guanajuato de 1887. II.3. Época de Porfirio Díaz. II.4. Ley de Enero de 1932. III. El notariado en el Estado de Guanajuato. IV. El notario auxiliar. V. Naturaleza jurídica. VI. Finalidad del notario auxiliar. VII. Derecho comparado en el notario auxiliar. VIII. Conclusiones. IX. Bibliografía.

Resumen. La figura del notario auxiliar se introdujo por primera vez en la Ley del Notariado del Estado de Guanajuato en el año 2012 al realizarse una serie de reformas a este marco normativo, la finalidad de la adición de esta figura, fue la actualización de la legislación notarial y a su vez, la de la vida práctica de las notarías públicas, pues el fenómeno de la globalización y la dinámica social, requerían que los notarios de esta entidad federativa no quedaran exentos del contexto jurídico global que se estaba haciendo cada día mas presente, en la actual vida social, y por supuesto, en la jurídica.

Palabras clave: ambigüedad, notario auxiliar, notarías públicas, globalización, contexto jurídico.

Abstract: The figure of the auxiliary notary was introduced by first time in the Notary Public of Guanajuato State Law in 2012 to realize a serial reforms in this regulatory framework, the purpose of adding this figure, was the updating of notarial legislation and the practice life in public notaries, since the phenomenon of globalization and social dynamics, requires that notaries of this federal state will not be exempt from the overall legal context that was becoming every day more present in current social life, and of course, the legal.

Keywords: ambiguity, auxiliary notary, public notaries, globalization, legal context.

\footnotetext{
1 Licenciado en Derecho, ex alumno de la División de Derecho, Política y Gobierno Campus Guanajuato, de la especialidad en Notario Público por la Universidad de Guanajuato.
} 


\section{INTRODUCCIÓN}

Los seres humanos en todos los tiempos han necesitado dar a sus relaciones jurídicas, un valor garantizador de lo que están realizando, se encuentra bajo el cuidado del Estado, pero sobretodo, posea un valor ante la sociedad que lo eleve a la verdad, le llamamos seguridad.

En el pasado, existió una búsqueda de juristas especializados y honestos para proporcionarla, sin embargo, en la actualidad es una necesidad, e inevitablemente, lo será también para la sociedad del futuro.

No existe un Estado en el mundo, donde no exista algún tipo de notariado, esta, es una institución realizadora de una función muy en la sociedad; no obstante, sus características o tipos pueden variar dependiendo de la nación a cual se aluda.

México se ubica dentro del grupo de países con un sistema jurídico de tradición romanística, es decir, un sistema que debe estar a cargo de abogados que aplican el derecho escrito y no el consuetudinario2, del cual, surge la importantísima figura del notario público o notariado latino, profesional altamente especializado en la ciencia del Derecho.

El notario, por definición, es un profesional del Derecho, a quién el Estado ha investido de fe pública, para ejercer la función notarial ${ }^{3}$, con características especiales y con un sello distintivo que tiene a su cargo el desempeño de una misión importante: recibir, interpretar y dar forma legal, a la voluntad de las partes, redactando los instrumentos adecuados a ese fin, confiriéndoles autenticidad, conservar los originales de éstos y expedir copias que den fe de su contenido. Lo que lo lleva a reunir en su calidad de fedatario público, la triple calidad de: profesionista, de depositario de la fe pública y como persona. ${ }^{4}$

Por lo anterior, al notario se le exige el conocimiento adecuado y científico del Derecho, al ser perito en esta ciencia, el notario público garantiza a las partes que el instrumento que redactó, cumple con todos los lineamientos legales y de forma que lo hagan eficaz, otorgando a la sociedad, la certeza y la seguridad jurídica, que brinda con su importantísima función.5

2 RÍOS HELLING, Jorge, La práctica del derecho notarial, 8ª ed., México, McGraw-Hill, 2012, p.28.

3 Ley del Notariado para el Estado de Guanajuato. Decreto 288 de la LXI Legislatura del H. Congreso del Estado de Guanajuato No. 154, Tercera parte, el 25 de septiembre del 2012. Art. $3^{\circ}$.

4 Grupo Parlamentario del Partido Acción Nacional, Iniciativa por la que se reforman, adicionan y derogan diversos dispositivos de la Ley del Notariado para el Estado de Guanajuato, exposición de motivos, México, Guanajuato, Guanajuato., Poder Legislativo Congreso del Estado de Guanajuato LXI Legislatura, agosto 2012, sitio de internet: http://www.congresogto.gob.mx/uploads/orden_archivo/archivo/238/8.pdf

5 Se entiende por función a toda actividad o conjunto de operaciones destinadas a un fin. Partimos desde el punto de vista de que la función notarial es una función pública. El fin del Estado es el bien común. Y para lograr ese fin, el Estado despliega funciones: legislativas, administrativas y jurisdiccionales. La función notarial sería una función pública administrativa, pues son actos concretos que satisfacen necesidades colectivas. Martínez Segovia, Francisco, Función notarial, Buenos Aires. 


\section{EL ORIGEN Y EVOLUCIÓN DEL NOTARIO AUXILIAR}

\section{II.1. EL IMPERIO DE MAXIMILIANO}

Nos situaremos primeramente desde la época del imperio de Maximiliano de Habsburgo, para ir conociendo la evolución y el origen del notario auxiliar.

El 30 de diciembre de 1865, el emperador Maximiliano de Habsburgo, expide la Ley Orgánica del Notariado y del Oficio de Escribano, fue publicada en la ciudad de Puebla, el 8 de febrero de 1866, esta ley, puso fin a los oficios públicos vendibles6. Se regulaba la figura del escribano, según el artículo 79, era un especie de Secretario de Tribunal o Juzgado quien solo prestaba servicio dentro de estos en los casos requeridos por la Ley llamándolos para intervenir.?

En el caso de los notarios auxiliares, esta ley en su artículo 19 rezaba: "en caso de enfermedad o impedimento temporal de un notario, puede comisionar para sustituirlo a otro notario público., en caso de que en el lugar no haya mas notarios, el sustituto será el juez de primera instancia o instrucción".

En este dispositivo legal, puede caber la posibilidad de ser precedente de los actuales capítulos de "la suplencia y sustitución" y de la "asociación de notarías", pues solo se permitía la sustitución del notario, por un notario en funciones, empero en la literalidad, no se estipulaba algún otro caso de sustitución o de suplencia.

\section{II.2. LEY ORGÁNICA DE ESCRIBANOS DEL ESTADO DE GUANAJUATO DE 1887}

Una vez fusilado Maximiliano de Habsburgo, el 10 de junio de 1887 se expide en el periódico oficial de Guanajuato, por el Coronel Luis Rivas Mercado, Gobernador Interino del Estado, la primer legislación para el notariado de la entidad, denominada Ley Orgánica de Escribanos del Estado de Guanajuato, ${ }^{9}$ que regulaba la actuación de los actuarios y notarios (Art. $\left.1^{\circ}\right),{ }^{10} \mathrm{y}$ en la cual el ejercicio de actuarios y notarios, ${ }^{11}$ no eran incompatibles, pues daba atribuciones exclusivas para cada uno, respectivamente.

En referencia a los auxiliares del notario, esta ley no los establecía con esta naturaleza, el artículo 41 rezaba: "en caso de enfermedad o impedimento temporal de un Notario Público, podrá este elegir otro que le substituya, previo aviso que deberá dar al Ayuntamiento respecti-

\footnotetext{
${ }^{6}$ Artículo 16.- "Previa la competente indemnización a los legítimos poseedores, se procederá a la extinción de los oficios públicos vendibles y renunciables."

7 VÁZQUEZ ALONSO, Nicolás, El notario auxiliar, origen, evolución y comentarios, México, sitio de internet: http://www.notario3.com/publicaciones/ORIGENYEVOLUCIONDELNOTARIOAUXILIAR.pdf. 22 de mayo de 2012.

8 Ley del Notariado para el Estado de Guanajuato, op. cit., nota 3, artículos 32 y 42, respectivamente.

9 Decreto No. 27 del XII Congreso Constitucional del Estado Libre y Soberano de Guanajuato, 10 de junio de 1887. Archivo Histórico del Estado.

10 Artículo 1".- "Los Escribanos se dividen en Actuarios y Notarios".

${ }^{11}$ De acuerdo a las definiciones que establecía la Ley Orgánica de Escribanos del Estado de Guanajuato de 1887, para los Actuarios y los Notarios, respectivamente, artículos $2^{\circ}$ y $3^{\circ}$, consideraba al Actuario como "al escribano destinado para autorizar los autos y decretos de los jueces, árbitros y arbitradores; y para practicar las diligencias que estos les encomienden, en los juicios civiles o criminales y en los actos de jurisdicción voluntaria", y al Notario como "los escribanos autorizados legalmente, para dar fe de los actos, contratos y últimas voluntades de las personas, para elevarlos a instrumentos públicos en los casos en que las Leyes los prevenga o permitan, y para expedir los certificados respectivos".
} 
vo", es decir, los notarios tenían la facultad de designar a otro Notario reemplazante para los efectos descritos, aunando el anterior dispositivo con el artículo 35 del mismo ordenamiento legal, señalaba: “...En caso de vacante por muerte, inhabilitación, incapacidad o ausencia de un Notario, cerrará inmediatamente su Protocolo, el que le suceda en el Despacho de la Notaría; y en caso de no haber sucesor, el que designe el Ayuntamiento del lugar, recibiendo el archivo de ella por inventario y a presencia de otro Notario interventor nombrado por el mismo Ayuntamiento...", dentro del mismo contexto legal, el artículo 66 estipulaba: "En caso de muerte, interdicción, ausencia, o cambio de domicilio de un Notario, si nadie le sucede en la Notaría, el Ayuntamiento respectivo nombrará un Notario que recogerá el archivo de aquel y su sello... En caso contrario, serán entregadas al Notario que legalmente le suceda en el Despacho..." 12

La Ley de 1887 , consideraba ante el caso de ausencia del Notario, debía ser siempre relevado en todos los casos, por otro Notario, ya sea por la voluntad del Notario substituido, o bien, por la designación del Ayuntamiento, mas nunca se figuraba a la vida jurídica, el notario auxiliar. Salvaguardando en todo momento la pericia y seguridad que brinda a la sociedad un notario, pues son cualidades inmersas dentro de su investidura y función.

\section{II.3. ÉPOCA DE PORFIRIO DÍAZ}

El 19 de diciembre de 1901, una década antes de concluir la época denominada Porfiriato en México, se expide la Ley del Notariado para el Distrito Federal y Territorios Federales. ${ }^{13}$

Esta ley era aplicable para el Distrito y los Territorios Federales existentes, en relación con los notarios auxiliares, se establecía en su artículo 24 "que el notario tendría la facultad de nombrar a un notario adscripto" y en la misma línea, el artículo 28 reformado señalaba "las faltas que ocurran en las Notarías, serían cubiertas por el nombramiento en el aspirante mas antiguo de la Notaría al momento de que ocurra la vacante", el artículo 36 marcaba "que en caso de enfermedad, ausencia o licencia del notario, sería el notario adscripto quien lo supliría en sus faltas", ${ }^{15}$ sin abundar mas al respecto. La ley únicamente se avocaba a los denominados "notarios adscriptos", aspirantes sustitutos para suplir las ausencias de un notario titular (véase nota 15).

\footnotetext{
${ }^{12}$ Decreto No. 27 del XII Congreso Constitucional del Estado Libre y Soberano de Guanajuato, op. cit., nota 9.

${ }^{13}$ PÉREZ FERNÁNDEZ DEL CASTILlO, Bernardo, Derecho Notarial, Ed. Porrúa, 18ª ed., México, 2012, p. 52.

${ }^{14}$ PÉREZ FERNÁNDEZ DEL CASTILLO, Bernardo, op. cit., nota 13, p. 191.

${ }^{15}$ El artículo 36 de esta ley, puede considerársele como el antecedente del concepto actual del notario suplente, solo se permitía la sustitución del notario en sus ausencias, por un aspirante al ejercicio del notariado denominado "adscripto". El notario "adscripto" o "adjunto", de acuerdo al artículo $3^{\circ}$ de la mencionada ley, eran los aspirantes al ejercicio del notariado que practicaban durante 6 meses en alguna notaria, como requisito previo para obtener su patente de aspirantes. En lo conducente, el actual artículo 11-A fracción IX, de la Ley del Notariado para el Estado de Guanajuato, estipula para ser aspirante a notario, el requisito de practicar durante un año por lo menos, en alguna de las notarías públicas del Estado, en similitud con aquel, para poder aspirar a tan digno cargo.
} 


\section{II.4. LEY DE ENERO DE 1932}

Esta nueva Ley, derogó a la de 1901, afirma y moderniza la anterior, conserva a los notarios titulares y a los adscritos, así como consolida el concepto de notario.

En lo concerniente al notario adscrito, se le otorga la facultad para actuar indistintamente con el titular e independientemente sin necesidad de recurrir a testigos de asistencia, para la autorización de cualquier acto. Suplía las faltas temporales, o en caso de cesación definitiva, lo anterior, si tenía un año de ejercicio, y si así no lo fuere, el nombramiento recaía sobre el aspirante a notario más antiguo. ${ }^{16}$

\section{EL NOTARIADO EN EL ESTADO DE GUANAJUATO}

La función notarial en el Estado de Guanajuato, en la actualidad corresponde al titular del Poder Ejecutivo, ${ }^{17}$ quien a través de la Secretaría de Gobierno, publicará una convocatoria para aquellos quienes cuenten con la calidad de aspirantes a notario, ${ }^{18}$ presenten el examen de oposición correspondiente, y una vez sustentado y aprobado, otorgar el fíat ${ }^{19}$ para el ejercicio de esta importante función.

\section{EL NOTARIO AUXILIAR}

A lo largo de la historia y, enfáticamente, en la actualidad, se le ha dado a la figura del notario auxiliar, diferentes denominaciones, por ello, es importante saber el significado de los diferentes adjetivos en su nominación; el Diccionario de la Real Academia de la Lengua Española,2o señala las siguientes definiciones para "auxiliar" y "adscrito", denominaciones de aclaración necesaria, para poder ahondar en la naturaleza de esta reciente figura. La palabra "auxiliar" proviene del latín auxiliaris, y significa: que auxilia, y a su vez, la palabra "auxilio", igualmente es una palabra derivada del latin "auxilium", y significa: ayuda, socorro, amparo. En lo concerniente a la palabra "adscrito", conjugada en presente infinitivo "adscribir", es una palabra que proviene del latín "adscribere”, y se define como: Inscribir, contar

\footnotetext{
${ }^{16}$ ARREDONDO RAMÍREZ, José Luis et al., Naturaleza jurídica de la función notarial, Tesis para obtener el título de Notario Público, México, Guanajuato, Gto., Universidad de Guanajuato, 1987, p.17.

${ }^{17}$ Artículo $1^{\circ}$ Ley del Notariado para el Estado de Guanajuato.- “... La función notarial corresponde al titular del Poder Ejecutivo, quien podrá conferir su ejercicio en los términos de esta ley, y deberá regirse por los principios de rogación, profesionalismo, imparcialidad, legalidad y autonomía en su ejercicio".

${ }^{18}$ De acuerdo al artículo 17-A de la Ley del Notariado del Estado de Guanajuato, la calidad de "aspirante a notario", se da cuando el participante a la convocatoria, previamente haya satisfecho los requisitos que la misma ley determina, y realice dos pruebas, una teórica, y una práctica, dividida por fases respectivamente.

${ }^{19}$ La Ley del Notariado del Estado de Guanajuato, no define literalmente lo que es el fiat en sí, éste se puede conceptualizar de manera implícita de este ordenamiento legal, consiste en la patente que el Poder Ejecutivo otorga a los abogados que han presentado el examen para aspirantes a notarios y de oposición para obtenerlo, y que los han acreditado. Es decir, el fiat, es el fundamento por medio del cual el Estado, a fin de garantizar la seguridad jurídica de los actos de los particulares, presume de veracidad entre el hecho o acto manifestado y que es exteriorizado en un documento, denominado instrumento, que el Notario redacta con su pericia, garantizando así, cualquier tipo de violación a los derechos de los gobernados.

${ }^{20}$ Real Academia Española, Diccionario de la Lengua Española, Ed. Espasa-Calpe, 2012, 22 ${ }^{\mathrm{a}}$ ed., Madrid, España.
} 
entre lo que corresponde a alguien o algo, o la segunda definición ad hoc para el tema la define como: Agregar a una persona al servicio de un cuerpo o destino.

La palabra notario es un sustantivo, es decir, tiene una existencia real, independiente e individual. Las palabras asociado, ${ }^{21}$ suplente,22 sustituto,23 auxiliar o adscrito, ${ }^{24}$ son adjetivos o hacen la función de este. Lo cual significa la modificación por estos términos del sustantivo, ${ }^{25}$ variando su esencia. Tal circunstancia resulta intrascendente, a menos que los adjetivos sean opuestos a la naturaleza del sustantivo. ${ }^{26}$

De las anteriores definiciones se puede concluir a la figura del notario auxiliar (auxiliaris: protector) o adscrito (adscrito: escribir junto), es la persona que se agrega o sustituye al funcionario que se encarga de dar fe y redactar actos jurídicos, como por ejemplo lo contratos y testamentos, dentro de la potestad o jurisdicción correspondiente.

Por su parte las leyes del Notariado establecen, que un notario auxiliar o adscrito, es el notario que designa el notario titular, después de haber cumplido determinados años de servicios, para que tenga las mismas facultades y actúen en el mismo protocolo, y que al faltar el titular, queda al frente de la notaría. En lo referente, el artículo 48-H de la Ley del Notariado para el Estado de Guanajuato, ${ }^{27}$ no establece concretamente una definición acerca del notario auxiliar, empero es el dispositivo legal en el cual, el legislador asentó lo mas cercano a la "naturaleza jurídica" de esta imprecisa figura (véanse notas 15, 18, 24 y 27).

Por su parte, el tratadista Carlos Emérito González, ${ }^{28}$ define al "notario auxiliar como: "El escribano adscripto creado por la Ley argentina, que consiste en actuar en el registro otorgado a un escribano titular, con los mismos deberes y atribuciones que éste, y con responsabilidad conjunta, cuando actúa, salvo la que deriva de la comisión de los delitos por los que responderá en forma exclusiva".

El doctrinista mexicano, Doctor y Notario Público, Bernardo Pérez Fernández del Castillo, ${ }^{29}$ señala como una de las vías para ser notario titular, es por adscripción, y consiste en el nombramiento por el titular de una notaria a un adscripto, aspirante a notario, quien

\footnotetext{
${ }^{21}$ El significado de la palabra asociado (consocio: concertar con, conspirar con alguien), según el Diccionario de la Real Academia de la Lengua Española, señala lo siguiente: "dícese de la persona que acompaña a otra en alguna comisión o encargo...". Por su parte, la Ley del Notariado para el Estado de Guanajuato, no define textualmente al notario asociado, únicamente hace referencia en su artículo 42 a que dos notarios pueden celebrar convenio de asociación, para actuar en un solo protocolo; asociación que podrán disolver en el momento que consideren necesario.

${ }^{22}$ El suplente es un notario con las mismas características, derechos y obligaciones del suplido que actúa en el protocolo del que está ausente. La actual Ley del Notariado del Estado de Guanajuato (artículo 32), obliga a los notarios, a celebrar un convenio de suplencia reciproca con otros notarios de la misma adscripción, para los casos de licencias, tiene como finalidad, que el servicio público prestado en una notaría, no sea suspendido por ausencia del notario titular.

${ }^{23}$ El notario sustituto, es la persona que se pone en el lugar o lo reemplaza al individuo que se encarga de dar fe y redactar actos jurídicos, que en este caso es al titular de la notaría,

${ }^{24} \mathrm{El}$ adscrito, es un aspirante a notario, no tiene protocolo propio, suple las faltas temporales del notario. La adscripción es voluntaria, por lo tanto hay notario que pueden actuar sin tener adscrito.

${ }^{25}$ De acuerdo con la definición del Diccionario de la Real Academia de la Lengua Española, al sustantivo lo define como lo "que tiene existencia real, independiente, individual, importante, fundamental, esencial." Real Academia Española, op. cit., nota 20.

${ }^{26}$ PEDRAZA, Enrique Antonio, El notario público. Funcionario al margen del Estado, México, 2008, p. 72.

${ }^{27}$ Artículo 48-H.- "El notario auxiliar colaborará en el ejercicio de la función del notario, actuará en el mismo protocolo y utilizará el mismo sello de autorizar y en su domicilio. El notario auxiliar harán constar ese carácter, indicándolo en todos los instrumentos".

${ }^{28}$ GONZÁLEZ, Carlos Emérito, "Derecho notarial”, Argentina, p. 152.

${ }^{29}$ PÉREZ FERNÁNDEZ DEL CASTILLO, Bernardo, op. cit, nota 13, p. 191.
} 
colabora con él y lo sustituye en sus faltas temporales, definitivas, fallecimiento o renuncia, el adscripto lo sustituye, convirtiéndose en titular. En palabras del ilustrísimo tratadista, menciona como en algunos casos, precisamente en el Estado de Guanajuato, ${ }^{30}$ se requiere presentar previamente un examen teórico-práctico.

\section{NATURALEZA JURÍDICA}

En la Constitución Política de los Estados Unidos Mexicanos, existe un capítulo denominado "De las responsabilidades de los servidores públicos", ${ }^{31}$ en dicho apartado, la Ley Fundamental, menciona quienes son los funcionarios y los servidores públicos. ${ }^{32}$ Se ha debatido ampliamente si el notario es o no es un funcionario público, una confusión recaída sobre la naturaleza jurídica del notario, pues su función es de orden público e interés social. El notario, en palabras de Jorge Ríos Helling, ${ }^{33}$ pertenece a una descentralización por colaboración, dentro de la administración pública, bajo esta modalidad, el Estado autoriza a los particulares, ya sean instituciones o personas, a que colaboren con él y desarrollen tareas en las que son especialistas, pero sin formar parte directa de la administración.

Por otro lado, la Ley Reglamentaria del artículo $5^{\circ}$ constitucional, relativa al ejercicio de las profesiones en el Estado de Guanajuato (conocida como Ley de Profesiones), comprende al abogado, que es el profesional del Derecho, dentro de la lista de profesiones. Disposición que se aúna con la Ley del Notariado del Estado de Guanajuato, ${ }^{34}$ al decir, el notario recibirá su retribución por la prestación del servicio al particular quien acude con este a pedirlos, cobrando de acuerdo a lo convenido entre ambos, o, en caso de falta de acuerdo para el pago, se tabulará con el arancel ${ }^{35}$ respectivo.

Estos dos aspectos, han suscitado la discusión sobre la naturaleza jurídica del notario. La ley lo considera un profesional del Derecho, y por ello, la profesión ha demostrado, quien tiene los conocimientos necesarios para actuar en la ciencia jurídica.36

Con lo expresado con antelación, el notario público es un funcionario nombrado por el ejecutivo estatal de manera directa o a través de un concurso por examen de oposición.

Sin embargo, existe la incongruencia pues los notarios a su vez, pueden nombrar o designar a otros notarios, con adjetivos, como son los notarios públicos asociados, los notarios suplentes, los sustitutos, los auxiliares o también llamados adscritos. En palabras de Enrique Antonio Pedraza,37 a manera de dar mas claridad y tratar de determinar la naturaleza jurídica del notario auxiliar, expresa en palabras coloquiales: "puedo decir, manzana roja, verde o amarilla, que son los colores de la manzana, pero no puedo decir, manzana azul, pues no existen las manzanas azules", de la misma manera, no se puede decir que "los perros

\footnotetext{
${ }^{30}$ Véase nota 18.

${ }^{31}$ Constitución Política de los Estados Unidos Mexicanos. Artículo 108.

${ }^{32}$ Al efecto la Suprema Corte de Justicia de la Nación en el siguiente criterio jurisprudencial: Tesis P./J. 75/2005, Semanario Judicial de la Federación y su Gaceta, Novena Época, t. XXII, julio de 2005, p. 795.

${ }^{33}$ RÍOS HELLING, Jorge, La práctica del derecho notarial, Ed. McGrawHill, 8a ed., México, 2012, p. 41.

34 Artículo $7^{\circ}$.- "Los notarios tendrán derecho a obtener de los interesados los gastos erogados en relación con el servicio y a cobrar honorarios que devenguen en cada caso...".

${ }^{35}$ Artículo $2^{\circ}$ de la Ley Arancelaria para el Cobro de Honorarios Profesionales de Abogados y Notarios y de Costas Procesales para el Estado de Guanajuato.- "A falta de contrato o de convenio entre el abogado o notario, y su cliente, regirán las disposiciones de esta ley".

${ }^{36}$ PÉREZ FERNÁNDEZ DEL CASTILLO, Bernardo, op. cit, nota 13, p. 179.

${ }^{37}$ Pedraza, Enrique Antonio, op. cit., nota 26, p. 56.
} 
maúllan, ni que los gatos ladran, ya que tales acciones no son propias de estos animales." ${ }^{8}$ Lo mismo sucede con los notarios auxiliares, no tienen razón de ser ni de existir, la función notarial la desempeña el Poder Ejecutivo del Estado, ${ }^{39}$ por tanto, es una facultad exclusiva de los gobernadores nombrar notarios. ${ }^{40}$ En el caso, es el notario, quien propone al Ejecutivo del Estado, el nombramiento de un notario auxiliar. ${ }^{41}$

Con esta condición el notario auxiliar, se convierte en un notario, por no haber recibido de acuerdo a los lineamientos jurídicos de origen, el nombramiento para ejercer la función, solo el titular de una notaría, debe "acreditar" la necesidad de tenerlo, agregando, una vez teniéndolo, éste puede ser removido del cargo, a solicitud del notario quien lo nombró, tal circunstancia hace respecto el nombramiento del notario auxiliar, no provenga del gobernador, sino de otro notario. ${ }^{42}$

\section{FINALIDAD DEL NOTARIO AUXILIAR}

Para saber cual fue, la finalidad de la inclusión de la figura del notario auxiliar a la Ley del Notariado para el Estado de Guanajuato, hay que atender primeramente, cual fue la ratio legis ${ }^{43}$ del legislador. En la exposición de motivos de la iniciativa por la que se reforman, adicionan y derogan diversos dispositivos de la Ley del Notariado para el Estado de Guanajuato, ${ }^{44}$ el legislador argumenta, como principal fuente de motivación para anexar esta figura, la actualización exigida por el fenómeno de la globalización ${ }^{45}$ y la dinámica social, así como aseverar una mejor calidad en la prestación del servicio; ${ }^{46}$ considera requerir un ordenamiento legal actualizado a los sucesos de la modernidad, permitiendo a los notarios Guanajuatenses tener un mejor desempeño en el ejercicio de su función. Manifiesta al notario auxiliar como su

\footnotetext{
${ }^{38}$ Idem.

39 Artículo $1^{\circ}$ de la Ley del Notariado para el Estado de Guanajuato.- “...La función notarial corresponde al titular del Poder Ejecutivo, quien podrá conferir su ejercicio en los términos de esta ley...”.

40 Artículo 11 de la Ley del Notariado para el Estado de Guanajuato.- "La creación de nuevas notarías será determinada por el Titular del Poder Ejecutivo...”.

${ }^{41}$ De acuerdo a la reforma del año 2012, el capítulo VII denominado Del notario auxiliar de la Ley del Notariado para el Estado de Guanajuato, regula lo referente a esta figura, en particular, el artículo que marca los requisitos para proponer a un notario auxiliar, es el artículo 48-B.

42 Cabe hacer mencionar, que se puede llegar a caer en el nepotismo, o que lazos de amistad o parentesco, lo compulsen o comprometan a actuar parcialmente, ya que la facultad de un notario titular, de proponer a un notario auxiliar, únicamente debe de acreditar la necesidad de tenerlo, sin que para ello, implique demostrar si la persona propuesta, cumple no solo con los requisitos de forma legal, sino con los requisitos deontológicos notariales, que deben ir inmersos sobre la persona que se propone a ocupar, para que se cumpla y no se viole con uno de los principios pilares de la función notarial, que es la imparcialidad.

La imparcialidad se define como "falta de designio anticipado o de prevención a favor o en contra de personas o cosas, de que resulta poderse juzgar o proceder con rectitud." Lo contrario a la imparcialidad es la parcialidad que propicia la corrupción y si ésta se da por dinero se denomina soborno o cohecho. Pérez Fernández del Castillo, Bernardo. Deontología notarial ética del notario y del aspirante, Ed. Porrúa, México, 2008, p. 20.

${ }^{43}$ La identidad de razón o ratio legis puede tener el significado de finalidad; se trata del "para que" de la norma. Para identificarla es necesario ir a la razón, motivo o finalidad que funda la justificación de la norma que será la base para crear la norma analógica. Ferrer Mac-Gregor et al., Eduardo. Diccionario de Derecho Procesal y Convencional, t.I., UNAM, 2014, pp. 88-89.

${ }^{44}$ Op. cit., nota 4.

${ }^{45}$ La globalización se define como "la tendencia de los mercados y de las empresas a extenderse, alcanzando una dimensión mundial que sobrepasa las fronteras nacionales.” Real Academia Española, op. cit., nota 20.

${ }^{46}$ El Sol del Bajío, Crean diputados figura de aspirante de notario, 14 de septiembre de 2012, sitio de internet: www.oem.com.mx/elsoldelbajio/notas/n2695327.htm
} 
adjetivo lo indica, auxilia al notario titular, quien tendrá los mismos derechos, obligaciones, impedimentos y sanciones en términos de la ley de aquel, pues ambos serán responsables de manera solidaria de su ejercicio notarial.

La propuesta trata de formar un espacio a personas con los conocimientos y la capacidad técnica para desenvolverse en la práctica notarial, como auxiliares y colaboradores de las Notarías Públicas del Estado de Guanajuato, más no prevé que, no es necesario traer a la vida jurídica, figuras ambiguas como lo es el notario auxiliar, sino mas bien, requiere legislar sobre la vida práctica-laboral, vivida día a día en las Notarías Públicas de la Entidad, donde los colaboradores y auxiliadores del notario en el desempeño de su función, deberían ser de suma importancia para su consideración y atención del legislador.

En los requisitos señalados en el artículo 48-B de la Ley Notarial en comento, la fracción III en concreto, señala si el notario titular que requiera de un notario auxiliar, deberá acreditar la necesidad de tenerlo, lo anterior, se confirmará al haber autorizado el notario titular en al año inmediato anterior de su ejercicio, un mínimo de quinientos actos notariales, entre otros.

$\mathrm{Al}$ aspirante a notario auxiliar, la ley determina, en su artículo 48-C, cumplir con la aprobación de un examen teórico práctico en los términos del mismo ordenamiento legal, acreditar tres años ininterrumpidos de prácticas notariales, y además, tener algunos de los tantos requisitos para aspirar a notario titular.

Si la finalidad del legislador fue la creación del notario auxiliar, ya sea por colaborar, suplir, sustituir, auxiliar, o asociar, la ley notarial ya preveía antes de la reforma, dichos adjetivos, sin necesidad de crear una figura confusa en el ámbito jurídico; o si de entre las finalidades de creación, fue para la colaboración entre el titular y el auxiliar, para garantizar una mejor calidad en los servicios prestados, también es del conocimiento general en una notaría colaboran varias personas, como lo son: la recepcionista, secretarias, abogados, etcétera; haciendo mas realce en estos últimos, pues también son profesionales del Derecho, y son de suma importancia su colaboración dentro de las notarías, pues ayudan en el desahogo y despacho de cada asunto efectuado ante el notario titular, dejando a salvo, el principio de imparcialidad ya referido. ${ }^{47}$

\section{DERECHO COMPARADO EN EL NOTARIO AUXILIAR}

En la República mexicana, existen Entidades Federativas, además del Estado de Guanajuato, ya incluían en sus respectivas leyes notariales, la figura del notario auxiliar, el Estado de Querétaro, es uno de ellos, en su ley notarial, específicamente en su Capítulo V, es denominado "De los notarios adscritos", describe que el notario adscrito48 "es aquél a quien el Ejecutivo le otorga el nombramiento como tal, a solicitud de un Notario Titular y previa satisfacción de los requisitos que se señalen en esta Ley", como podemos observar, entre el Estado de Queré-

\footnotetext{
47 Véase nota 42.

${ }^{48}$ Ley del Notariado para el Estado de Querétaro, Artículo 36.
} 
taro y Guanajuato, no existe muchas diferencias en lo concerniente a la posible definición ${ }^{49}$ y naturaleza de esta figura.

Otro de los Estados dentro de la República que habla en su Ley Notarial ${ }^{50}$ respecto a los notarios auxiliares, es Puebla, en esta entidad, la ley menciona uno de los caracteres como puede actuar el notario, es el del auxiliar, y lo define como "el designado con tal carácter por el Ejecutivo, a propuesta del Notario titular", en similitud con los Estados de Querétaro y Guanajuato, los notarios auxiliares poblanos ${ }^{51}$ tienen las mismas facultades del titular, actuar en el mismo protocolo, con el mismo sello del titular, y suplirlo en caso de ausencia.

El Estado de Veracruz, es otro de los que cuenta en su ley notarial, el notario adscrito, lo define ${ }^{52}$ como "el aspirante al ejercicio del notariado que designa al Ejecutivo a propuesta de un Notario titular para sustituirlo en su ausencias temporales, con plenitud de funciones e iguales obligaciones, responsabilidades e impedimentos." $\mathrm{Su}$ definición, sigue la misma línea de los mencionados Estados, sus funciones y obligaciones son en esencia las mismas.

Un Estado del país, con unas de las mas sofisticadas leyes en la materia notarial, es Colima, el 1 de noviembre del año 2014, fue publicada en el periódico oficial de la entidad, las mas reciente reforma en este ámbito del Derecho, cabe hacer mencionar, acerca de los notarios colimenses, a consideración propia, cuentan con una de las leyes mas detalladas en cuanto al contenido jurídico respecta, en esta materia, y sin poder dejar de hacer un realce en esta ley, adhirió, la figura del protocolo electrónico, lo que convierte al Estado de Colima, en uno de los mas avanzados en la implantación de este nuevo modelo notarial. La dinámica social y la globalización, sobretodo en esta materia del Derecho, debe obligar a los notarios de todas las entidades federativas, se adapten a las nuevas tecnologías, debido a la importancia implícita en el constante dinamismo social cuya alusión hace el legislador guanajuatense en la redacción de su exposición de motivos $^{53}$ para la implementación de la figura del notario auxiliar. Si no se actualiza el notariado ante todos los cambios de este aspecto, estará destinado a convertirse en un oficio anacrónico por su manera de operar. Lo que no se adapta, esta condenado a desaparecer, ${ }^{54}$ para actuar con eficacia, es un deber del notario adaptarse técnica y jurídicamente al mundo moderno. En referencia al notario auxiliar, la ley notarial colimense, hace las mismas veces que las leyes notariales de los Estados de Chiapas, Durango, Querétaro, Puebla, Veracruz, Guanajuato, Jalisco, Baja California Sur, Tabasco, Nayarit, Zacatecas, Baja California, San Luis Potosí, Hidalgo, Quintana Roo, Tlaxcala, Oaxaca y Tamaulipas, con las obligaciones, funciones y prohibiciones dentro del contexto jurídico que se le atribuyen a la figura del notario auxiliar

El Estado de Sinaloa, en referencia al notario auxiliar, tiene una particularidad, denominan notario auxiliar, a otros notarios con jurisdicción distinta, o incluso a otro de diferente

\footnotetext{
${ }^{49}$ Véase nota 27.

${ }^{50}$ Capítulo Tercero denominado "Del carácter de la actuación del Notario", Ley del Notariado para el Estado de Puebla, artículo 22 y 24 respectivamente.

${ }^{51}$ Título Quinto "De los notarios auxiliares, asociados y substitutos", Ley del Notariado para el Estado de Puebla, artículo 65.

${ }^{52}$ Ley del Notariado para el Estado de Veracruz, artículo 6o.

${ }^{53}$ Véase nota 4.

${ }^{54}$ En el Estado de Guanajuato, el sistema de protocolo electrónico aún no es una forma de operación en las Notarías Públicas de la entidad, sin embargo, existen autores que ya han hablado sobre implementar este nuevo modelo, como lo es el del caso del Lic. Francisco Javier Zárate Ponce, en su tesis titulada Protocolo Electrónico, manifiesta la importancia de anexar esta nueva forma de operar en las notarias de la entidad. Zárate Ponce, Francisco Javier, Protocolo Electrónico, Tesis para obtener el título de la especialidad de Notaría Pública, México, Guanajuato, Gto., Universidad de Guanajuato, 2003, 63 h.
} 
entidad federativa, si su ley se los permite, para auxilie, al notario de origen, en el caso de una escritura o acta pasada ante cualquiera de estos, pueda ser firmada por los otorgantes ante otro notario de jurisdicción distinta, lo anterior, si cumple con los requisitos marcados por el mismo dispositivo. ${ }^{55}$

Los Estados de Morelos, Sonora, Yucatán y Nuevo León, le atribuyen diferente denominación al notario auxiliar, sus leyes notariales, por su parte, los llaman notarios suplentes.

Los Estados de Chihuahua, Guerrero, México, Aguascalientes, Campeche, Coahuila, Michoacán y el Distrito Federal, no integran en su ley notarial, la figura del notario auxiliar.

\section{CONCLUSIONES}

PRIMERA.- A lo largo del tiempo y de la Historia, el notario público, en nuestro país ha desarrollado su actividad, de manera personalísima, en el cual no cabe la posibilidad de delegar dicha investidura, pues su naturaleza siempre, proviene del Poder Ejecutivo, y no de una potestad o facultad facilitada por éste, y aunque, sea a discreción del mismo titular, proponer al Ejecutivo la necesidad de tenerlo, aceptar la propuesta de un notario titular para adherir a un notario auxiliar, es ya en sí incompatible.

SEGUNDA.- La creación a la vida jurídica de la figura del notario auxiliar, no tiene razón de ser ni de existir, es una figura ambigua, como se ha visto, a lo largo de la Historia y en la actualidad, los notarios auxiliares, han sido creados por el legislador, con diferentes denominaciones, o mejor dicho adjetivos, con la finalidad de, como su nombre lo dice, auxiliar al titular de la notaría, en el desahogo, despacho, colaboración de los asuntos realizados en la notaría pública, por lo tanto su naturaleza y actividad, es meramente laboral, y no jurídicamente útil para la sociedad.

TERCERA.- La adhesión del notario auxiliar, en algunas de las diferentes legislaturas notariales de los Estados de la República, es signo de que se ha seguido el mismo patrón de derechos, obligaciones, responsabilidades, sanciones y prohibiciones para esta confusa figura, la naturaleza del auxiliar es solidariamente la misma a la de un notario titular, sin embargo, existe la salvedad de que los notarios auxiliares, pueden ser destituidos en el momento así considerado oportuno para el notario de origen, quedando inservible la necesidad de anexarlo a la vida práctica de la notaría, haciendo destacar la imposibilidad de existir dos notarios laborando al mismo tiempo en una notaría, pues puede provocar confusión y desprestigio en la profesión.

CUARTA.- La finalidad del legislador de crear al notario auxiliar, fue la necesidad de otorgar a la ciudadanía por parte de las notarías públicas del Estado, un mejor servicio y la modernización del sector a causa de los constantes cambios sociales en el mundo; mas no prevé un eje central de la efectividad laboral para darse en la vida diaria de las notarias públicas, pues los verdaderos colaboradores de los notarios titulares, son su trabajadores. Por las características propias de su función, los colaboradores de un notario, en su mayoría deben ser Abogados o Licenciados en Derecho, pues además del notario, ellos poseen la capacidad y los conocimientos técnicos requeridos para el mejor desempeño laboral de la notaria, y la productividad jurídica que se realiza en el interior de la notaría.

\footnotetext{
${ }^{55}$ Ley del Notariado para el Estado de Sinaloa, artículo 96.
} 
BIBLIOGRAFÍA

ARREDONDO RAMÍREZ, José Luis et al., Naturaleza jurídica de la función notarial, Tesis para obtener el título de Notario Público, México, Guanajuato, Gto., Universidad de Guanajuato, 1987, p.17.

FERRER MAC-GREGOR et al., Eduardo. Diccionario de Derecho Procesal y Convencional, t.I., UNAM, 2014, pp. 88-89.

GONZÁLEZ, Carlos Emérito, “Derecho notarial”, Argentina, p. 152.

PEDRAZA, Enrique Antonio, El notario público. Funcionario al margen del Estado, México, 2008, p. 72.

PÉREZ FERNÁNDEZ DEL CASTILLO, Bernardo, Derecho Notarial, Ed. Porrúa, $18^{a}$ ed., México, 2012, p. 52.

_ _ _ _ , Deontología notarial ética del notario y del aspirante, Ed. Porrúa, México, 2008, p. 20.

REAL ACADEMIA ESPAÑOLA, Diccionario de la Lengua Española, Ed. Espasa-Calpe, 2012, 22 $2^{\mathrm{a}}$ ed., Madrid, España.

RÍOS HELLING, Jorge, La práctica del derecho notarial, 8a ed., México, McGraw-Hill, 2012, p.28.

ZÁRATE PONCE, Francisco Javier, Protocolo Electrónico, Tesis para obtener el título de la especialidad de Notaría Pública, México, Guanajuato, Gto., Universidad de Guanajuato, 2003, $63 \mathrm{~h}$.

LEGISLACIÓN

Constitución Política de los Estados Unidos Mexicanos.

Decreto No. 27 del XII Congreso Constitucional del Estado Libre y Soberano de Guanajuato, 10 de junio de 1887. ARCHIVO HISTÓRICO DEL ESTADO.

Ley del Notariado para el Distrito Federal.

Ley del Notariado para el Estado de Aguascalientes.

Ley del Notariado para el Estado de Baja California Sur.

Ley del Notariado para el Estado de Baja California.

Ley del Notariado para el Estado de Campeche.

Ley del Notariado para el Estado de Chiapas.

Ley del Notariado para el Estado de Chihuahua.

Ley del Notariado para el Estado de Coahuila.

Ley del Notariado para el Estado de Colima.

Ley del Notariado para el Estado de Durango. 
Ley del Notariado para el Estado de Guanajuato. Decreto 288 de la LXI Legislatura del H.

Congreso del Estado de Guanajuato No. 154, Tercera parte, el 25 de septiembre del 2012. Art. $3^{\circ}$.

Ley del Notariado para el Estado de Guerrero.

Ley del Notariado para el Estado de Hidalgo.

Ley del Notariado para el Estado de Jalisco.

Ley del Notariado para el Estado de México.

Ley del Notariado para el Estado de Michoacán.

Ley del Notariado para el Estado de Morelos.

Ley del Notariado para el Estado de Nayarit.

Ley del Notariado para el Estado de Nuevo León.

Ley del Notariado para el Estado de Oaxaca.

Ley del Notariado para el Estado de Puebla.

Ley del Notariado para el Estado de Querétaro.

Ley del Notariado para el Estado de Quintana Roo.

Ley del Notariado para el Estado de San Luis Potosí.

Ley del Notariado para el Estado de Sinaloa.

Ley del Notariado para el Estado de Sonora.

Ley del Notariado para el Estado de Tabasco.

Ley del Notariado para el Estado de Tamaulipas.

Ley del Notariado para el Estado de Tlaxcala.

Ley del Notariado para el Estado de Veracruz.

Ley del Notariado para el Estado de Yucatán.

Ley del Notariado para el Estado de Zacatecas.

JURISPRUDENCIA

Tesis P./J. 75/2005, Semanario Judicial de la Federación y su Gaceta, Novena Época, t. XXII, julio de 2005, p. 795.

SITIOS WEB CONSULTADOS

El Sol del Bajío, Crean diputados figura de aspirante de notario, 14 de septiembre de 2012, sitio de internet: www.oem.com.mx/elsoldelbajio/notas/n2695327.htm 
Grupo Parlamentario del Partido Acción Nacional, Iniciativa por la que se reforman, adicionan y derogan diversos dispositivos de la Ley del Notariado para el Estado de Guanajuato, exposición de motivos, México, Guanajuato, Guanajuato., Poder Legislativo Congreso del Estado de Guanajuato LXI Legislatura, agosto 2012, sitio de internet: http://www.congresogto.gob.mx/uploads/orden_archivo/archivo/238/8.pdf

Vázquez Alonso, Dr. Nicolás, El notario auxiliar, origen, evolución y comentarios, México, sitio de internet: http://www.notario3.com/publicaciones/ORIGENYEVOLUCIONDELNOTARIOAUXILIAR.pdf. 22 de mayo de 2012. 